ARIADNA B. ŁADA

MARIA KAŹMIERCZAK

University of Gdańsk, Institute of Psychology, Poland

\title{
NEGATIVE AROUSABILITY \\ AND RELATIONSHIP SATISFACTION: THE MEDIATING ROLE OF EMPATHY
}

Temperamental traits and empathy are both associated with emotional regulation; they thus shape both the quality of an individual's life and the functioning of his or her social relationships. However, the mediating effects of emotional empathy in the relationship between temperamental characteristics and relationship satisfaction have not been closely analyzed and therefore require further study. This study examined the effects of temperamental arousability - global negative arousability and its components (fear, sadness, discomfort, frustration) - on emotional empathy and, consequently, on relationship satisfaction. One hundred and fifty young adults (104 women, 46 men) aged 20 to 35 participated in the study. The participants had been in romantic relationships for at least six months. The study used a sociodemographic survey and a set of questionnaires which included the Adult Temperament Questionnaire - Short Form, the Empathic Sensitiveness Scale and the RELAT Questionnaire. The results showed that empathic concern fully mediated the relationship between global negative arousability and relationship satisfaction. Furthermore, the effects of fear and sadness on relationship satisfaction were fully mediated by empathic concern and personal distress. Additionally, personal distress fully mediated the relationship between discomfort and relationship satisfaction. Neither empathic concern nor personal distress were mediators in the relationship between frustration and relationship satisfaction. It can therefore be concluded that although partners who exhibit higher global negative arousability report lower relationship satisfaction, they might become more satisfied when being more compassionate and caring towards others.

Keywords: temperament; negative arousability; empathy; relationship satisfaction.

Corresponding author: ARIADNA B. LADA - University of Gdańsk, Institute of Psychology, ul. Bażyńskiego 4, 80-309 Gdańsk, Poland; e-mail: ariadna.lada@ug.edu.pl

The protocol of this study was approved by the Ethics Board for Research Projects at the Institute of Psychology, University of Gdansk, Poland (decision no. 7/2018). Prior to the study, written informed consent was obtained from all participants. The preparation of this paper was supported by Grant for Young Scientists and Doctoral Students no. 538-7400-B190-18 from the University of Gdansk. 


\section{INTRODUCTION}

Emotions constitute a crucial aspect of intimate relationships. Partners experience and interpret the emotional climate in their relationship, which might be more or less positive, leading to variations in relationship satisfaction, with mediational effects of the partners' responsiveness (Caughlin \& Huston, 2006). For this reason, many authors have emphasized the importance of individual dispositions related to emotional regulation and responsiveness, including temperamental traits or empathy, in shaping partners' functioning in romantic relationships (Bakker \& Demerouti, 2009; Boyce, Wood, \& Ferguson, 2016; Davis \& Kraus, 1991; Dey \& Ghosh, 2016; Loudin, Loukas, \& Robinson, 2003). This study focused on emotional arousability and empathy as predictors of satisfaction in romantic relationships.

\section{Negative arousability and relationship satisfaction}

Individual differences in arousability have been linked with differences in optimal levels of stimulation between individuals. Higher or lower demand for stimulation is associated with approaching or withdrawing from highly stimulating situations (Rothbart \& Bates, 1998; Strelau, 2015). Such tendencies reflect differences in the intensity of reactions to various types of stimuli (external or internal, emotional or sensory, etc.). However, reactivity to emotional stimuli is typically linked with temperament (Rothbart \& Bates, 1998). Strelau (2015) emphasizes that emotional reactivity is mainly expressed in negative emotions. Studies have indicated that this dimension can be compared with neuroticism (Strelau \& Zawadzki, 1995). Therefore, self-regulatory processes are required to support the processing of stimuli in order to maintain optimal stimulation levels (Eliasz, 1981; Rothbart, Ellis, \& Posner, 2004).

There is much research linking neuroticism to lower relationship satisfaction. Partners who avoid stimuli might feel more lonely and less secure in their relationships. A higher intensity of reactions to stimuli has also been associated with the risk of conflicts or divorce. People with higher negative arousability (negative affect) feel more irritated and frustrated, which makes them use exit and neglect tactics more frequently in conflict situations with their partner; they often use emotion-focused coping strategies, which are only effective in the short term, and so they cope poorly with serious relationship problems (Berry \& Willingham, 1997; Friedman \& Förster, 2001; Keltner, Gruenfeld, \& Anderson, 2003; 
Simpson, Winterheld, \& Chen, 2006). Furthermore, when they encounter relationship difficulties, they not only have stronger negative emotional reactions but also notice more negative features and behaviors in their partners and pay more attention to them than to the positive ones - thus strengthening the negative reaction cycle and affecting relationship satisfaction (Simpson et al., 2006).

\section{Emotional empathy and relationship satisfaction}

Empathy is a complex concept which includes various emotional components, the most frequently analyzed of which are empathic concern/sympathy and personal distress (Davis, 1983, 1999). These components of empathy are both closely linked to emotional regulation processes (Ali \& Alea, 2017; Eisenberg \& Okun, 1996; Okun, Shepard, \& Eisenberg, 2000; Richards, Butler, \& Gross, 2003). Empathic concern refers to other-oriented feelings - to compassion, sorrow, or concern for other people in difficult situations - whereas personal distress is associated with self-oriented feelings - the tendency to experience fear, anxiety, distress, or discomfort in response to other people's strong negative experiences (Davis, 1983; Eisenberg \& Okun, 1996; Kaźmierczak, Plopa, \& Retowski, 2007).

Research indicates that partners who are more willing to emotionally support each other and engage in mutual communication have a greater tendency to take into account the perspective of others and be emotionally responsive to the affective states and reactions of others (Kaźmierczak, 2008; Levesque, Lafontaine, Caron, Flesch, \& Björnson, 2014). They are more empathically concerned for others partly due to their high ability to regulate negative emotions (Kaźmierczak, 2008; Kaźmierczak \& Plopa, 2012). Therefore, the aspects of empathy associated with good emotional regulation have been linked to higher relationship satisfaction, commitment, and mutual respect (Levesque et al., 2014; Perrone-McGovern et al., 2014; Sened et al., 2017). In contrast, a greater inclination to empathically experience other people's negative emotions as one's own (personal distress) might predict self-deprecating behaviors and lower relationship satisfaction (Kaźmierczak, 2008, 2015).

\section{Negative arousability and emotional empathy}

Research has indicated that while empathic concern and personal distress are both associated with higher negative emotional intensity, only personal distress is 
also correlated with low levels of emotional regulation (Eisenberg \& Eggum, 2009; Eisenberg \& Fabes, 1992; Kaźmierczak, 2008). The tendency to empathically experience negative emotions (personal distress) may cause overarousal, which can encourage the use self-focus as a survival strategy in emotionally difficult situations (Eisenberg \& Fabes, 1992). On the other hand, studies are inconsistent regarding the relationship between empathic concern and emotional regulation (Eisenberg, 2010). This might be due to the fact that, unlike personal distress, empathic concern provokes moderate levels of arousal (Eisenberg \& Fabes, 1992). Still, positive associations between sympathy and helping others in need have been emphasized, even in situations which are easy to escape (Eisenberg \& Okun, 1996; Nadler, Fisher, \& Streufert, 1976; Okun et al., 2000), indicating better interpersonal functioning.

In line with the abovementioned results, Eisenberg and Fabes (1992) believe that individual differences in reactions and behaviors related to empathy depend to some extent on individual differences in coping with emotional arousal (Eisenberg \& Fabes, 1992; Eisenberg \& Okun, 1996; Okun et al., 2000). Thus, it is understandable that emotional empathy has been found to be predicted by individual differences in temperament (e.g., Bryant, 1990), as it has been linked to trait arousability in the interpersonal context (Mehrabian, 1996). In consequence, more emotionally empathic individuals are more sensitive to all interpersonal cues, even those that are less relevant (Mehrabian, Young, \& Sato, 1988). Additionally, previous studies have found that temperamental factors better explain the heritability of emotional empathy than cognitive empathy (Davis, Luce, \& Kraus, 1994; Melchers, Montag, Reuter, Spinath, \& Hahn, 2016). However, research in this domain has often focused on the predictors of empathy (e.g., studies on children having a twin brother or sister). Thus, there is a gap in research on the effects of temperament (as related to reactivity to negative emotional cues) and emotional empathy, measured simultaneously, on the quality of close relationships.

Still, temperamental negative affectivity has been regarded as part of the avoidance orientation in close relationships (e.g., intimacy being perceived as threatening, a focus on negative aspects of the relationship, poor management of conflicts, or lower relationship satisfaction; Simpson et al., 2006). However, the mediating effects of emotional empathy in the relationship between temperamental negative affectivity and relationship satisfaction have not been closely analyzed. 


\section{The aim of the study}

The aim of this study was to investigate the effects of negative arousability global negative arousability and its components (fear, frustration, sadness, and discomfort) - on emotional empathy and, subsequently, on relationship satisfaction. We hypothesized that higher levels of negative arousability and its components would be associated with higher personal distress and empathic concern (Hypothesis 1). Additionally, we hypothesized that higher levels of negative arousability and its components would predict lower relationship satisfaction (Hypothesis 2). We also hypothesized that the relationship between negative arousability and relationship satisfaction would be mediated by two components of emotional empathy: empathic concern and personal distress, with the former correlating positively and the latter negatively with relationship satisfaction (Hypothesis 3).

\section{METHOD}

\section{Participants and procedure}

The participants in the study were 150 young adults (104 women, 46 men) aged 20 to $35\left(M_{\text {age }}=23.74, S D=3.26\right)$. The analyses showed that the differences in age between women $\left(M_{\text {age }}=23.54, S D=3.17\right)$ and men $\left(M_{\text {age }}=24.20\right.$, $S D=3.43)$ were not statistically significant $\left(t_{(148)}=-1.14 ; p=.26\right.$; Cohen's $d=.20$ ), but the women's mean age was lower than men's. Each participant had been involved in a romantic relationship for at least six months. The average relationship duration was 3.5 years $(S D=2.44$; relationship duration ranged from 0.5 to 10.5 years). Only $9.3 \%$ of the participants were married. All participants were childless, but $92 \%$ reported a desire to have children in the future. A total of $49.3 \%$ of the participants lived with their partners, while $50.7 \%$ did not share a household with theirs. In the whole sample, $32.7 \%$ of participants had graduated from universities, $57.3 \%$ were students, and $10 \%$ had graduated from high school. The participants were asked to complete a sociodemographic survey and a set of questionnaires.

In order to determine the sample size for a mediation analysis, we conducted a power analysis using $\mathrm{G}^{*}$ Power (Faul, Erfelder, Buchner, \& Lang, 2008). With a large effect size $\left(f^{2}\right)$ of .35 , an alpha of .05 , and a power level of .95 , the results of the power analysis showed that a minimum of 53 participants would be 
needed for this study to achieve an appropriate power level. Therefore, the sample of 150 participants was sufficient.

Females were overrepresented in this study, which is common in social sciences. This is mainly due to the fact that women are more open to participation in such research and more curious, especially when it comes to issues concerning relationships. Moreover, participation in the study was voluntary and no remuneration was provided for it.

\section{Measures}

We used the Adult Temperament Questionnaire (ATQ) - Short Form (Evans \& Rothbart, 2007), as adapted into Polish by Cieciuch et al. (unpublished manuscript), to measure temperamental traits. Dispositional empathy was examined using the Empathic Sensitiveness Scale (SWE; Kaźmierczak et al., 2007). To assess satisfaction with romantic relationships, we used the RELAT Questionnaire as adapted by Kaźmierczak \& Rostowska (2010).

Adult Temperament Questionnaire (ATQ) - Short Form. The ATQ Short Form assesses temperament on four scales: Effortful Control, Negative Affect, Extraversion/Surgency, and Orienting Sensitivity, as well as its 13 subscales. It consists of 77 items with a 7-point Likert response scale (1 - extremely untrue of you; 4 - neither true nor false of you; 7 - extremely true of you). Due to the research objectives of this study, we analyzed only the negative affect factor. This factor comprises four subscales: Fear - related to the anticipation of distress (e.g., "Sometimes, I feel a sense of panic or terror for no apparent reason"); Sadness - depressed mood and energy, the result of exposure to suffering, object loss, or disappointment (e.g., "Sometimes minor events cause me to feel intense sadness"); Discomfort - related to sensory qualities of stimulation (e.g. "I find certain scratchy sounds very irritating"); and Frustration - associated with the interruption of ongoing tasks or goal pursuit (e.g., "Whenever I have to sit and wait for something (e.g. a waiting room), I become agitated"). The higher the score, the higher the tendency towards fear, sadness, discomfort, and frustration. The values of Cronbach's $\alpha$ in this study were as follows: .66 for Fear, .69 for Sadness, .76 for Discomfort, and .65 for Frustration. Cronbach's $\alpha$ for the Negative Affect scale was .83.

Empathic Sensitiveness Scale (SWE). This questionnaire measures dispositional empathy, understood as the tendency towards express empathic concern (compassion and caring for others in need), personal distress (experiencing negative emotions when observing someone in discomfort or suffering), and perspec- 
tive taking (cognitive empathy; a tendency to take someone else's point of view). It consists of 28 items with a 5-point Likert response scale $(1$ - completely disagree; 3 - hard to say; 5 - absolutely agree). Due to the research objectives of the study, we analyzed the scores on two subscales: Empathic Concern and Personal Distress. These empathic components are associated with emotional regulation processes. The higher the score, the higher the reported level of empathy. In this study, Cronbach's $\alpha$ was .77 for Empathic Concern and .80 for Personal Distress.

RELAT Questionnaire. This scale measures satisfaction with a romantic/marital relationship (Rostowska \& Kaźmierczak, 2010). It consists of seven items related to satisfaction with the functioning of various areas of the relationship, with a 5-point Likert response scale (1 - I'm definitely not satisfied; 3 - I have no opinion; 5 - I'm definitely satisfied). The respondents assess how satisfied they are, for instance, with the love experienced, the amount of time spent together, or the ways conflicts are resolved in the relationship. The total score is the sum of the responses to all items. The higher the score, the more satisfied the partners are with their relationship. In the present study, Cronbach's $\alpha$ for the scale was .72.

\section{RESULTS}

Table 1 presents descriptive statistics and Pearson's $r$ correlations between the variables in the model. Global negative arousability and, particularly, fear and sadness were positively correlated with empathic concern. A significant positive correlation was also found between personal distress and global negative arousability - particularly fear, frustration, and sadness. Moreover, the analyses showed that frustration and personal distress negatively correlated with relationship satisfaction. No statistically significant correlations were found between relationship satisfaction and other variables. 
Table 1. Descriptive Statistics and Correlations Between Temperamental Traits, Empathy, and Relationship Satisfaction

\begin{tabular}{lllllllll}
\hline & 1 & 2 & 3 & 4 & 5 & 6 & 7 & 8 \\
\hline 1. Fear & 1 & & & & & & & \\
2. Frustration & $.30^{* *}$ & 1 & & & & & & \\
3. Sadness & $.47^{* *}$ & $.29^{* *}$ & 1 & & & & & \\
4. Discomfort & $.49^{* *}$ & $.23^{* *}$ & $.36^{* *}$ & 1 & & & & \\
5. Negative Arousability & $.80^{* *}$ & $.60^{* *}$ & $.74^{* *}$ & $.73^{* *}$ & 1 & & & \\
6. Empathic Concern & $.32^{* *}$ & .08 & $.57^{* *}$ & .12 & $.39^{* *}$ & 1 & & \\
7. Personal Distress & $.55^{* *}$ & $.37^{* *}$ & $.47^{* *}$ & $.49^{* *}$ & $.63^{* *}$ & $.30^{* *}$ & 1 & \\
8. Relationship Satisfaction & -.09 & $-.23^{* *}$ & -.20 & -.08 & -.14 & .13 & $-.19^{*}$ & 1 \\
\hline$\quad M$ & 3.75 & 4.05 & 4.62 & 4.05 & 4.12 & 39.03 & 23.49 & 29.75 \\
$\quad S D$ & 1.04 & 0.99 & 0.97 & 1.13 & 0.75 & 6.18 & 5.70 & 3.63 \\
\hline$N o$. & & & & & & & & \\
\hline
\end{tabular}

Note. $* p<.05, * * p<.001$.

To test the hypothesis that the impact of global negative arousability as a temperamental trait on relationship satisfaction is mediated by the emotional dimensions of empathy, we performed mediation analyses. Using the PROCESS bootstrapping macro (Hayes, 2013), we entered global negative arousability and its components (fear, frustration, sadness, and discomfort) as predictors, the emotional dimensions of empathy (empathic concern and personal distress) as the hypothesized mediators, and relationship satisfaction as the dependent variable (we applied Model 6 of analysis in the PROCESS bootstrapping macro). Age and relationship length were added as covariates in the mediation analysis.

The analysis indicated that the effect of global negative arousability on relationship satisfaction through the mediating effect of emotional empathy was significant only for empathic concern (see Figure 1). The effect of global negative arousability on relationship satisfaction was fully mediated by empathic concern; the bootstrap confidence interval for the indirect effect $(b=0.41)$ based on 5000 bootstrap samples was entirely above zero (0.104 to 0.813 ; see Figure 1$)$. Thus, we found no direct effect of global negative arousability on relationship satisfaction $(b=-0.58, \mathrm{SE}=0.52, t=-1.11, p=.27,95 \% \mathrm{CI}$ for $b=[-1.610,0.455])$. However, we did find a direct effect of empathic concern on relationship satisfaction $(b=0.13, \mathrm{SE}=0.05, t=2.55, p=.01,95 \% \mathrm{CI}$ for $b=[0.029,0.229])$. $R^{2}$ for the model was $.10 ; F(5,144)=4.75, p=.007$. There was no effect 
of either covariate on relationship satisfaction. Thus, although partners with higher global negative arousability report lower relationship satisfaction, they might become more satisfied when being more compassionate and caring for other people.

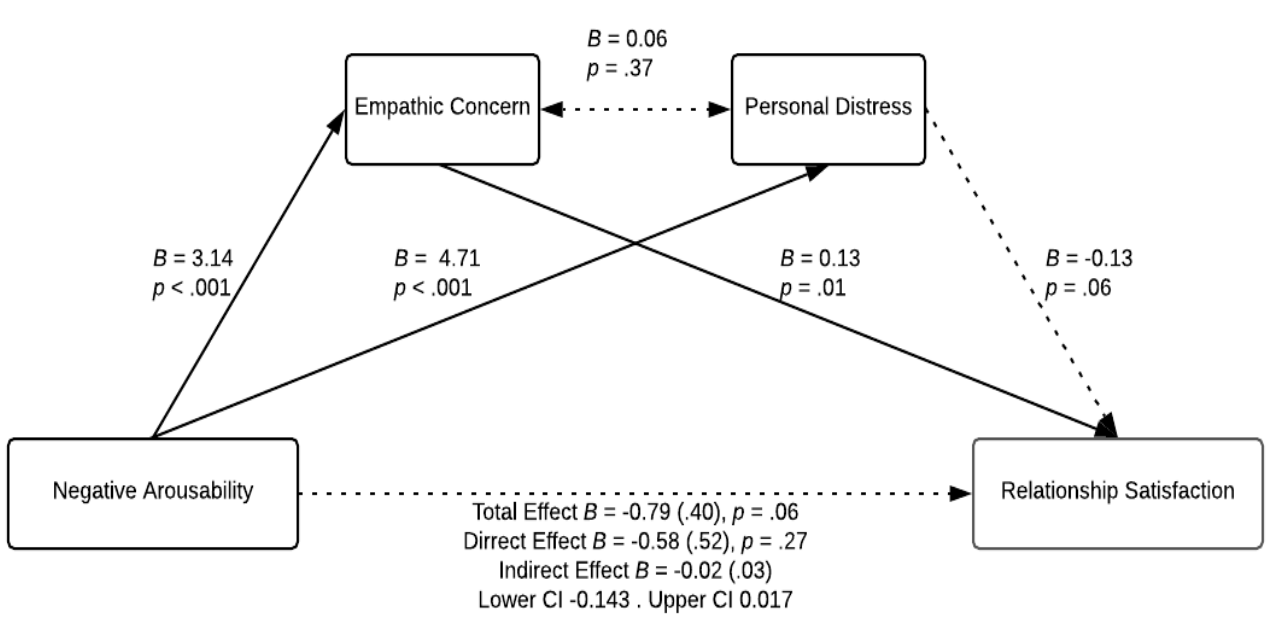

Figure 1. Relationship between Negative Arousability and Relationship Satisfaction mediated by Empathic Concern and Personal Distress.

Note. Standard errors are provided in parentheses.

We also conducted mediation analysis with components of global negative arousability as predictors, empathic concern and personal distress as the hypothesized mediators, and relationship satisfaction as the dependent variable. This analysis showed that the effect of fear on relationship satisfaction was fully mediated by both empathic concern and personal distress separately, but no direct effect was found between them $(b=0.12, \mathrm{SE}=0.07, t=1.85, p=.07,95 \% \mathrm{CI}$ for $b=$ [- 0.008, 0.257]; see Figure 2). We found no direct effect of fear on relationship satisfaction $(b=-0.10, \mathrm{SE}=0.34, t=-0.28, p=.78,95 \% \mathrm{CI}$ for $b=[-0.771,0.577])$. However, we did find direct effects of empathic concern $(b=0.012, \mathrm{SE}=0.05, t=2.35, p=.02,95 \% \mathrm{CI}$ for $b=[0.019,0.216])$ and personal distress $(b=-0.16, \mathrm{SE}=.06, t=-2.60, p=.01,95 \% \mathrm{CI}$ for $b=[-0.281$, -0.038]) on relationship satisfaction. For empathic concern, the bootstrap confidence interval for the indirect effect $(b=.22)$ based on 5000 bootstrap samples was entirely above zero [.032 to .523], whereas for personal distress, the boot- 
strap confidence interval for the indirect effect $(b=-0.44)$ based on 5000 bootstrap samples was entirely below zero $(-0.821$ to -0.106$) . R^{2}$ for the model was $.10 ; F(5,144)=3.04, p=.01)$. Moreover, there was a significant difference between indirect effects for empathic concern and personal distress as mediators between fear and relationship satisfaction $(b=0.66, \mathrm{SE}=0.23,95 \% \mathrm{CI}$ for $b=[0.222,1.153])$. As in the case of negative arousability, also in the case of fear there was no significant effect of either covariate (age or relationship length) on relationship satisfaction.

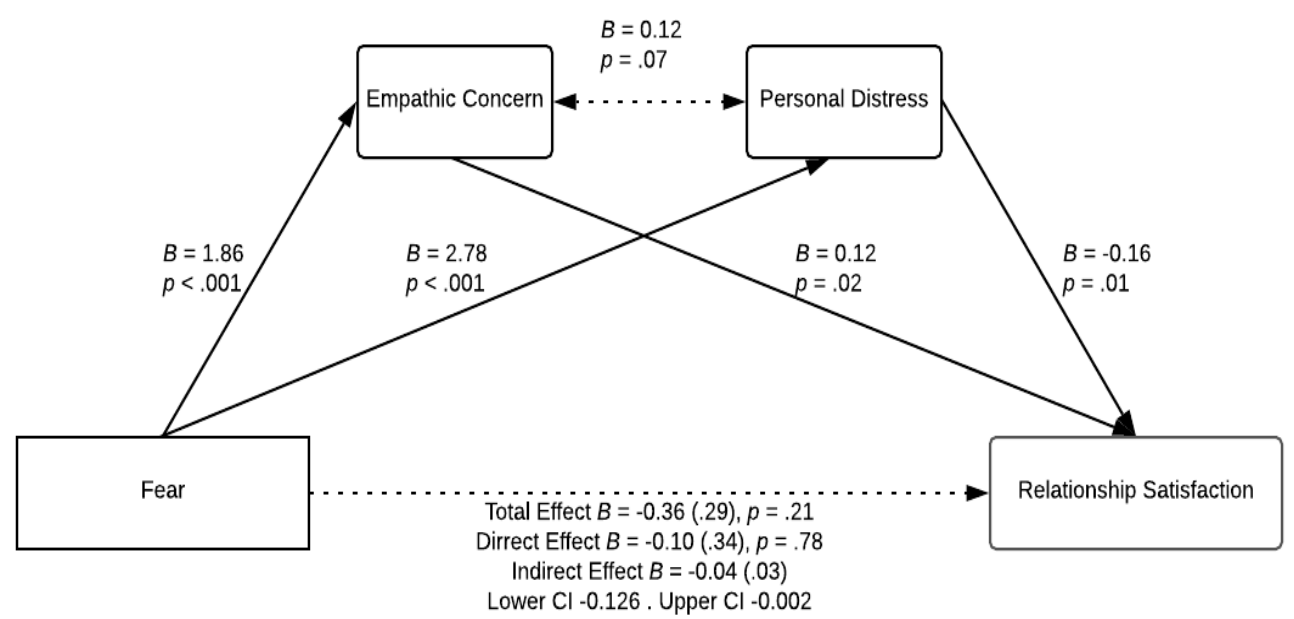

Figure 2. Relationship between Fear and Relationship Satisfaction mediated by Empathic Concern and Personal Distress.

Note. Standard errors are provided in parentheses.

The results also indicate that the effect of sadness on relationship satisfaction was fully mediated by both empathic concern and personal distress separately, but no direct effect was found between them $(b=0.04, \mathrm{SE}=0.08, t=0.43$, $p=.67,95 \% \mathrm{CI}$ for $b=[-0.128,0.198])$; there was also a non-significant indirect effect of sadness on relationship satisfaction through empathic concern and personal distress in serial (bootstrap confidence interval for the indirect effect $b=.01$ based on 5000 bootstrap samples was [-0.552 to 0.553]; see Figure 3). We found no direct effect of sadness on relationship satisfaction $(b=-0.11$, $\mathrm{SE}=0.39, t=-0.29, p=.77,95 \% \mathrm{CI}$ for $b=[-0.889,0.661])$. However, we found direct effects of empathic concern $(b=0.12, \mathrm{SE}=0.06, t=2.16, p=.03$, 
95\% CI for $b=[0.010,0.236])$ and personal distress $(b=-0.16, \mathrm{SE}=0.06$, $t=-2.81, p=.01,95 \% \mathrm{CI}$ for $b=[-0.276,-0.048])$ on relationship satisfaction. For empathic concern, the bootstrap confidence interval for the indirect effect $(b=0.44)$ based on 5000 bootstrap samples was entirely above zero [0.087 to 0.848], whereas for personal distress the bootstrap confidence interval for the indirect effect $(b=-0.43)$ based on 5000 bootstrap samples was entirely below zero [-0.868 to -0.086$]. R^{2}$ for the model was $.10 ; F(5,144)=3.04, p=.01$. Moreover, there was a significant difference between indirect effects for empathic concern and personal distress as mediators between sadness and relationship satisfaction $(b=0.87, \mathrm{SE}=0.27,95 \% \mathrm{CI}$ for $b=[0.349,1.445])$. As before, for sadness there was no significant effect of either covariate (age or relationship length) on relationship satisfaction.

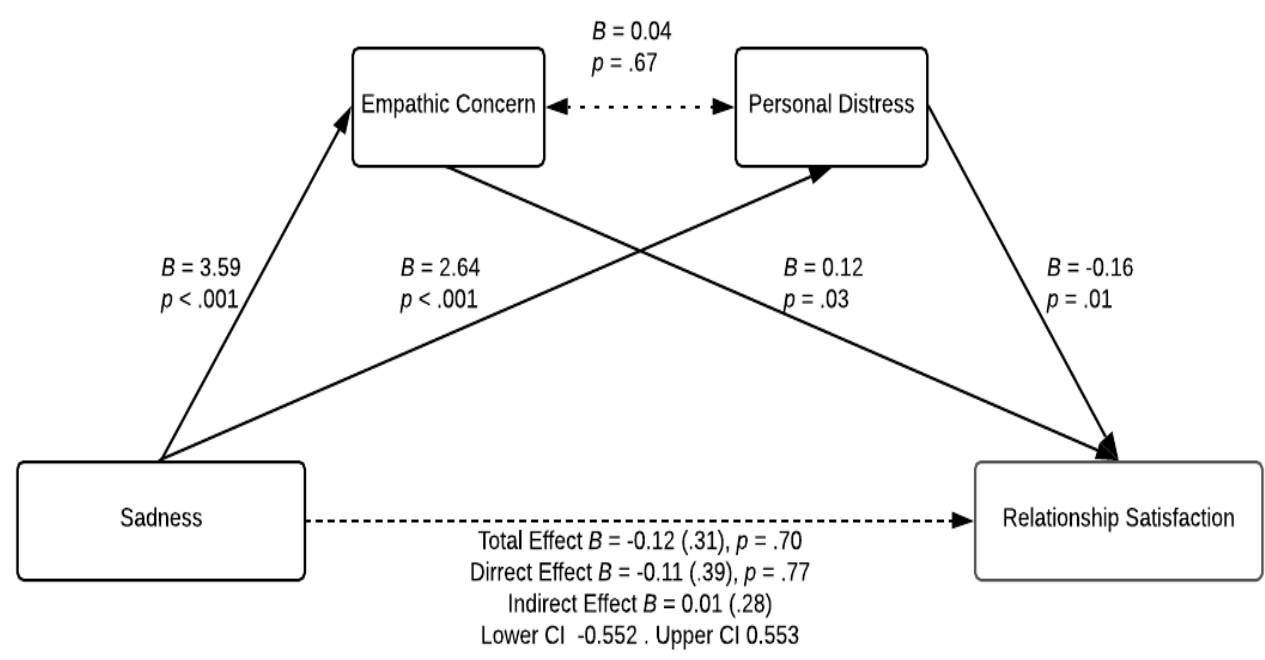

Figure 3. Relationship between Sadness and Relationship Satisfaction mediated by Empathic Concern and Personal Distress.

Note. Standard errors are provided in parentheses.

Furthermore, mediation analysis showed that the effect of discomfort on relationship satisfaction with emotional empathy as mediator was significant only for personal distress (see Figure 4). The effect of discomfort on relationship satisfaction was fully mediated by personal distress; the bootstrap confidence interval for the indirect effect $(b=-0.34)$ based on 5000 bootstrap samples was entirely below zero [-0.629 to -0.118]. Thus, we found no direct effect of discomfort on 
relationship satisfaction $(b=-0.02, \mathrm{SE}=0.29, t=-0.08, p=.93,95 \% \mathrm{CI}$ for $b=[-0.591,0.543])$. We did, however, find a direct effect of personal distress on relationship satisfaction $(b=-0.17, \mathrm{SE}=0.06, t=-2.85, p=.01,95 \% \mathrm{CI}$ for $b=[-0.282,-0.051]) . R^{2}$ for the model $=.10 ; F(5,144)=3.02, p=.01$. There was no effect of either covariate on relationship satisfaction. Neither age nor relationship length as covariates had a significant effect on relationship satisfaction.

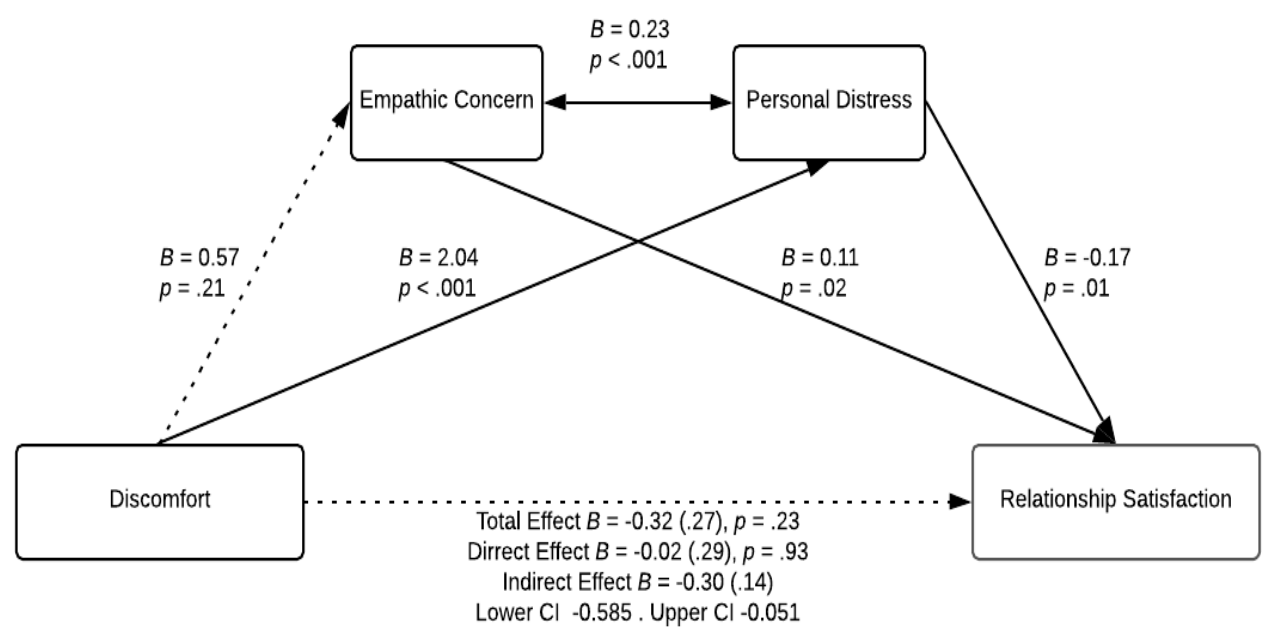

Figure 4. Relationship between Discomfort and Relationship Satisfaction mediated by Empathic Concern and Personal Distress.

Note. Standard errors are provided in parentheses.

The analysis also indicated that the effect of frustration on relationship satisfaction with empathic concern and personal distress as mediators was not significant. However, we found a direct effect of frustration on relationship satisfaction $(b=-0.68, \mathrm{SE}=0.31, t=-2.22, p=.03,95 \% \mathrm{CI}$ for $b=[-0.234,-0.013])$.

\section{DISCUSSION}

This study examined associations between negative arousability, emotional empathy, and relationship satisfaction in a sample of young adults. We focused on global negative arousability (and its components: fear, frustration, sadness, and discomfort) and emotional empathy (empathic concern and personal dis- 
tress), as both are closely related to emotional regulation processes and responsiveness and therefore influence relationship satisfaction (Okun et al., 2000; Richards et al., 2003; Levesque et al., 2014; Perrone-McGovern et al., 2014).

The correlational analyses showed that the higher their global negative arousability - fear and sadness in particular - the more inclined the young adults were to feel compassion and care towards others in need as well as to experience negative emotions when observing someone in discomfort or suffering. Furthermore, the higher the negative arousability associated with the interruption of ongoing tasks or with the blocking of goal pursuit and the higher the sensory qualities of stimulation, the more inclined the participants were to experience negative emotions in response to other people's suffering or discomfort (Levesque et al., 2014; Perrone-McGovern et al., 2014; Sened et al., 2017). The above results confirm Hypothesis 1. Therefore, as stated in the introduction, both analyzed dimensions of empathy are associated with high reactivity to emotional stimuli (Eisenberg, 2005). However, empathic concern is also accompanied by better functioning of regulatory processes. In other words, despite high emotional reactivity, empathic concern is related to better control over arousal - i.e., to better control over focusing on or shifting attention away from stimuli (Eisenberg \& Eggum, 2009). It is therefore more cognitively complex and linked to empathically taking the perspective of others (Hoffman, 2003, 2006) or to other cognitive processes (Eisenberg, 2010).

The aforementioned differences in the conceptualization of empathic concern and personal distress were reflected in subsequent mediational analyses. On the one hand, in the mediational models, global negative arousability (as well as sadness and fear) was associated with higher empathic concern, which means it facilitated compassion and caring for others. These results confirm the higher sensitivity of partners with higher empathic concern scores to various interpersonal cues (Mehrabian et al., 1988), which increases relationship satisfaction. On the other hand, the mediational models revealed that fear, sadness, and discomfort were positively related to personal distress, indicating higher negative emotional intensity and difficulties in emotional regulation, leading to lower relationship satisfaction. This latter mediating effect might be evidence of the avoidance orientation in an intimate relationship (Simpson et al., 2006). Therefore, although global negative arousability and its components (with repeated effects of sadness and fear) predicted lower relationship satisfaction in the mediational models (confirmation of Hypothesis 2), these tendencies have also been related to better assessment of relationships, due to positive associations with empathy. Hence, while global negative arousability (or its components) and emotional empathy 
dimensions were found to be positively associated in this study, the effects on relationship satisfaction differed depending on the particular mediator in the model (confirmation of Hypothesis 3). Relationship satisfaction increased when higher negative arousability was accompanied by positive interpersonal tendencies such as kindness, displaying support, openness to other people's feelings and needs, or constructive conflict management (all related to empathic concern; see e.g., Davis, 1999). Referring to Eisenberg and Fabes (1992), we can conclude that, in this case, the regulation of negative emotions was more effective when empathic concern was a mediator than when personal distress was a mediator. Self-focusing while empathically resonating negative emotions has been previously associated with destructive reactions in close relationships (Kaźmierczak, 2008) and might indicate overarousal.

It should be added that Batson, in his numerous works (e.g., 2009, 2010), concluded that higher personal distress implies low ability to withstand high stimulation in stressful conditions, for example when observing other people's pain. Thus, in the context of this study, partners with higher personal distress in close relationships might display difficulties in coping with highly emotional situations and react ineffectively - for instance, by engaging in conflict or refusing to support their partner. In consequence, by dealing poorly with negative emotions, such partners might experience a decrease in relationship satisfaction. In contrast, partners presenting higher empathic concern have, by definition, a tendency to show support and actively deal with emotionally stressful situations, even at a cost to themselves (Eisenberg, 2010). Such constructive reactions might lead to increased relationship satisfaction, as our study confirmed.

The analyses of dimensions of emotional empathy (empathic concern and personal distress) as mediators of the relationship between fear and sadness with relationship satisfaction were significant. The detrimental effect of negative arousability, related to the anticipation of distress and sadness, disappears when emotional responsiveness to other people's affective states and reactions is added to the model. In contrast, experiencing discomfort was associated with personal distress, which indicates poorer coping with negative emotions. Presumably, this also suggests the tendency to escape from difficult situations with high levels of negative emotions (Perrone-McGovern et al., 2014). Surprisingly, though correlational analyses indicated that frustration was associated with both personal distress and relationship satisfaction, its impact on relationship satisfaction was not mediated by personal distress. This may be due to the significant main effects of frustration and personal distress on relationship satisfaction (Eisenberg \& Okun, 1996; Levesque et al., 2014). 
The above findings also suggest that empathic concern and personal distress seem to be counteracting each other and produce a suppressing effect. An interesting direction of future research would be to investigate which characteristics of the relationship help to activate empathic concern in individuals with higher negative arousability and which of them favor mediating mechanism through personal distress.

\section{LIMITATIONS}

This research has several limitations. First, our sample was of medium size and consisted mostly of participants who had not formally legalized their relationship (i.e., who were unmarried). Moreover, we analyzed individuals in relationships but we did not analyze couples, so we may have omitted specific factors related to their functioning. An assessment of couples should be included in further research. Finally, we used a correlational design, which does not allow conclusions to be drawn about cause-effect associations.

\section{REFERENCES}

Ali, S., \& Alea, N. (2017). Does who I am or how I regulate matter? Consequences of manipulation of emotion regulation strategies. The International Journal of Aging \& Human Development, 85(2), 135-163. DOI: 10.1177/0091415016682252

Bakker, A. B., \& Demerouti, E. (2009). The crossover of work engagement between working couples: A closer look at the role of empathy. Journal of Managerial Psychology, 24(3), 220-236. DOI: 10.1108/02683940910939313

Batson, C. (2009). These things called empathy: Eight related but distinct phenomena. In J. Decety \& W. Ickes (Eds.), The social neuroscience of empathy (pp. 16-31). Cambridge, MA, US: MIT Press.

Batson, C. (2010). Empathy-induced altruistic motivation. In M. Mikulincer \& P. R. Shaver (Eds.), Prosocial motives, emotions, and behavior: The better angels of our nature (pp. 15-34). Washington, DC, US: American Psychological Association. DOI: 10.1037/12061-001

Berry, D. S., \& Willingham, J. K. (1997). Affective traits, responses to conflict, and satisfaction in romantic relationships. Journal of Research in Personality, 31, 564-576.

Boyce, C. J., Wood, A. M., \& Ferguson, E. (2016). For better or for worse: The moderating effects of personality on the marriage-life satisfaction link. Personality and Individual Differences, 97, 61-66. DOI: https://doi.org/10.1016/j.paid.2016.03.005

Bryant, B. K. (1990). Mental health, temperament, family, and friends: Perspectives on children's empathy and social perspective taking. In N. Eisenberg \& J. Strayer (Eds.), Empathy and its development (pp. 245-270). Cambridge, UK: Cambridge University Press. 
Caughlin, J. P., \& Huston, T. L. (2006). The affective structure of marriage. In A. L. Vangelisti \& D. Perlman (Eds.), The Cambridge handbook of personal relationships (pp. 131-155). New York, NY, US: Cambridge University Press.

Davis, M. H. (1983). Measuring individual differences in empathy: Evidence for a multidimensional approach. Journal of Personality and Social Psychology, 44(1), 113-126.

Davis, M. H. (1999). Empatia. O umiejętności wpółodczuwania [Empathy. The ability to empathize]. Gdańsk, Poland: Gdańskie Wydawnictwo Psychologiczne.

Davis, M. H., \& Kraus, L. (1991). Dispositional empathy and social relationships. Advances in Personal Relationships, 3, 75-115.

Davis, M. H., Luce, C., \& Kraus, S. J. (1994). The heritability of characteristics associated with dispositional empathy. Journal of Personality, 62(3), 369-391. DOI: 10.1111/j.1467-6494. 1994.tb00302.x

Dey, S., \& Ghosh, J. (2016). Factors in the distribution of successful marriage. International Journal of Social Sciences and Management, 3(1), 60-64.

Eisenberg, N. (2005). Empatia i współczucie [Empathy and compassion]. In M. Lewis \& J. M. Haviland-Jones (Eds.), Psychologia emocji (M. Kacmajor et al., Trans.; pp. 849-867) [Psychology of emotions]. Gdańsk, Poland: Gdańskie Wydawnictwo Psychologiczne.

Eisenberg, N. (2010). Empathy-related responding: Links with self-regulation, moral judgment, and moral behavior. In M. Mikulincer \& P. R. Shaver (Eds.), Prosocial motives, emotions, and behavior: The better angels of our nature (pp. 129-148). Washington, DC, US: American Psychological Association. DOI: 10.1037/12061-007

Eisenberg, N., \& Eggum, N. D. (2009). Empathic responding: Sympathy and personal distress. In J. Decety \& W. Ickes (Eds.), The social neuroscience of empathy (pp. 71-83). Cambridge, MA, US: MIT Press.

Eisenberg, N., \& Fabes, R. A. (1992). Emotion, regulation, and the development of social competence. In Emotion and social behavior (pp. 119-150). Thousand Oaks, CA, US: Sage Publications, Inc.

Eisenberg, N., \& Okun, M. A. (1996). The relations of dispositional regulation and emotionality to elders' empathy-related responding and affect while volunteering. Journal of Personality, 64(1), 157-183. DOI: 10.1111/j.1467-6494.1996.tb00818.x

Eliasz, A. (1981). Temperament a system regulacji stymulacji [Temperament and the stimulation regulation system]. Warszawa, Poland: Państwowe Wydawnictwo Naukowe.

Evans, D. E., \& Rothbart, M. K. (2007). Developing a model for adult temperament. Journal of Research in Personality, 41(4), 868-888. DOI: https://doi.org/10.1016/j.jrp.2006.11.002

Faul, F., Erdfelder, E., Buchner, A., \& Lang, A.-G. (2008). $G^{*}$ Power Version 3.1.2 [computer software]. Uiversität Kiel, Germany. Retrieved from http://www.psycho.uni-duesseldorf.de/ abteilungen/aap/gpower3/download-and-register

Friedman, R. S., \& Förster, J. (2001). The effects of promotion and prevention cues on creativity. Journal of Personality and Social Psychology, 81(6), 1001-1013.

Hayes, A. F. (2013). Introduction to mediation, moderation, and conditional process analysis: A regression-based approach. New York, NY, US: The Guilford Press.

Hoffman, M. L. (2003). Empathy and moral development. Implications for caring and justice. New York, NY, US: Cambridge University Press.

Hoffman, M. L. (2006). Empatia i rozwój moralny (O. Waśkiewicz, Trans.). [Empathy and moral development]. Gdańsk, Poland: Gdańskie Wydawnictwo Psychologiczne. 
Kaźmierczak, M. (2008). Oblicza empatii w relacjach matżeńskich [The faces of empathy in marital relationships]. Gdańsk, Poland: Wydawnictwo UG.

Kaźmierczak, M. (2015). Oblicza empatii w procesie adaptacji do rodzicielstwa [The faces of empathy in the process of adaptation to parenthood]. Warszawa, Poland: Wydawnictwo Naukowe Scholar.

Kaźmierczak, M., \& Plopa, M. (2012). Komunikacja w bliskich zwiazkach. Teoria i metoda badania. [Communication in close relationships. Theory and method of research]. Warszawa, Poland: Vizja Press \& IT.

Kaźmierczak, M., Plopa, M., \& Retowski, S. (2007). Skala Wrażliwości Empatycznej [The Empathic Sensitiveness Scale]. Przeglad Psychologiczny, 50(1), 9-24.

Kaźmierczak, M., \& Rostowska, T. (2010). Percepcja relacji małżeńskich i poziom empatii partnerów a jakość życia [The perception of marital relationships and the level of partners' empathy and the quality of life]. In T. Rostowska \& A. Peplinska (Eds.), Psychospoteczne aspekty życia rodzinnego [Psychosocial aspects of family life] (pp. 110-124). Warszawa, Poland: Wydawnictwo Diffin.

Keltner, D., Gruenfeld, D. H., \& Anderson, C. (2003). Power, approach, and inhibition. Psychological Review, 110, 265-284. DOI: 10.1037/a0026811

Levesque, C., Lafontaine, M.-F., Caron, A., Flesch, J. L., \& Björnson, S. (2014). Dyadic empathy, dyadic coping, and relationship satisfaction: A dyadic model. Europe's Journal of Psychology, 10(1), 118-134. DOI: 10.5964/ejop.v10i1.697

Loudin, J. L., Loukas, A., \& Robinson, S. (2003). Relational aggression in college students: Examining the roles of social anxiety and empathy. Aggressive Behavior, 29(5), 430-439. DOI: $10.1002 / a b .10039$

Mehrabian, A. (1996). Pleasure-arousal-dominance: A general framework for describing and measuring individual differences in temperament. Current Psychology: A Journal for Diverse Perspectives on Diverse Psychological Issues, 14(4), 261-292. DOI: 10.1007/BF02686918

Mehrabian, A., Young, A. L., \& Sato, S. (1988). Emotional empathy and associated individual differences. Current Psychology: A Journal for Diverse Perspectives on Diverse Psychological Issues, 7(3), 221-240. DOI: 10.1007/BF02686670

Melchers, M., Montag, C., Reuter, M., Spinath, F. M., \& Hahn, E. (2016). How heritable is empathy? Differential effects of measurement and subcomponents. Motivation and Emotion, 40(5), 720-730.

Nadler, A., Fisher, J. D., \& Streufert, S. (1976). When helping hurts: Effects of donor-recipient similarity and recipient self-esteem on reactions to aid1. Journal of Personality, 44, 392-409. DOI: 10.1111/j.1467-6494.1976.tb00129.x

Okun, M. A., Shepard, S. A., \& Eisenberg, N. (2000). The relations of emotionality and regulation to dispositional empathy-related responding among volunteers-in-training. Personality and Individual Differences, 28(2), 367-382. DOI: https://doi.org/10.1016/S0191-8869(99)00107-5

Perrone-McGovern, K. M., Oliveira-Silva, P., Simon-Dack, S., Lefdahl-Davis, E., Adams, D., McConnell, J., ... Gonçalves, Ó. F. (2014). Effects of empathy and conflict resolution strategies on psychophysiological arousal and satisfaction in romantic relationships. Applied Psychophysiology and Biofeedback, 39(1), 19-25. DOI: 10.1007/s10484-013-9237-2

Richards, J. M., Butler, E. A., \& Gross, J. J. (2003). Emotion regulation in romantic relationships: The cognitive consequences of concealing feelings. Journal of Social and Personal Relationships, 20(5), 599-620. DOI: 10.1177/02654075030205002 
Rothbart, M. K., \& Bates, J. E. (1998). Temperament. In W. Damon (Series Ed.) \& N. Eisenberg (Vol. Ed.), Social, emotional, and personality development. Vol. 3: Handbook of child psychology (pp. 105-176). New York, NY, US: Wiley.

Rothbart, M. K., Ellis, L. K., \& Posner, M. I. (2004). Temperament and self-regulation. In R. F. Baumeister \& K. D. Vohs (Eds.), Handbook of self-regulation: Research, theory, and applications (pp. 357-370). New York, NY, US: Guilford Press.

Sened, H., Lavidor, M., Lazarus, G., Bar-Kalifa, E., Rafaeli, E., \& Ickes, W. (2017). Empathic accuracy and relationship satisfaction: A meta-analytic review. Journal of Family Psychology, 31(6), 742-752. DOI: 10.1037/fam0000320

Simpson, J., Winterheld, H., \& Chen, J. (2006). Personality and relationships: A temperament perspective. In A. Vangelisti \& D. Perlman (Eds.), The Cambridge handbook of personal relationships (pp. 231-250). New York, NY, US: Cambridge University Press.

Strelau, J. (2015). Różnice indywidualne [Individual differences]. Warszawa, Poland: Wydawnictwo Naukowe SCHOLAR.

Strelau, J., \& Zawadzki, B. (1995). Podstawy teoretyczne, konstrukcja i własności psychometryczne inwentarza „Formalna Charakterystyka Zachowania Kwestionariusz Temperamentu" [Theoretical foundations, structure, and psychometric properties of the Formal Characteristics of Behavior - Temperament Questionnaire]. Studia Psychologiczne, 33, 49-96. 